Originalien

Med Klin Intensivmed Notfmed 2020 115:300-306 https://doi.org/10.1007/s00063-019-0599-y

Received: 11 December 2018

Revised: 15 May 2019

Accepted: 29 June 2019

Published online: 7 August 2019

(c) Springer Medizin Verlag $\mathrm{GmbH}$, ein Teil von

Springer Nature 2019

\section{Redaktion}

M. Buerke, Siegen
F. S. Magnet ${ }^{1,5} \cdot$ E. Heilf $f^{1,2,5}$ - S. E. Huttmann ${ }^{1,5}$. J. Callegari ${ }^{1,5}$ - S. B. Schwarz ${ }^{1,5}$.

\section{J. H. Storre ${ }^{3,4} \cdot$ W. Windisch ${ }^{1,5}$}

'Department of Pneumology, Cologne Merheim Hospital, Kliniken der Stadt Köln gGmbH, Cologne, Germany

${ }^{2}$ Department of Internal Medicine, Park-Klinik Weissensee, Berlin, Germany

${ }^{3}$ Department of Intensive Care, Sleep Medicine and Mechanical Ventilation, Asklepios Fachkliniken

Munich-Gauting, Munich, Germany

${ }^{4}$ Department of Pneumology, University Medical Hospital, Freiburg, Germany

${ }^{5}$ Faculty of Health/School of Medicine, Witten/Herdecke University, Witten, Germany

\title{
The spontaneous breathing trial is of low predictive value regarding spontaneous breathing ability in subjects with prolonged, unsuccessful weaning
}

\section{Introduction}

Weaning from invasive mechanical ventilation is an essential and universal element in the care of critically ill patients, particularly in those with weaning difficulties [3]. The time spent on the weaning process is estimated to represent $40-50 \%$ of the total duration of mechanical ventilation on the ICU $[6,8,10,18]$. Accordingly, three different weaning categories were defined at an International Consensus Conference in 2005 and published in 2007: 'simple', 'difficult' and 'prolonged' [3]. Importantly, these categories are fundamentally based on the spontaneous breathing trial (SBT).

The SBT is a well-established tool in ICU medicine for predicting how successful the outcome of extubation will be $[7,8,13]$. According to the International Consensus Conference, SBT failure criteria are defined both by subjective indices (e.g. depressed mental status, diaphoresis, cyanosis) and objective measurements (e.g. low $\mathrm{PaO}_{2}$ values, high $\mathrm{PaCO}_{2}$ values, low $\mathrm{pH}$ values or a high rapid shallow breathing index [RSBI]) [3]. Here, the first $30 \mathrm{~min}$ are crucial to the success of the SBT $[7,30]$. The reintubation rate is reportedly at only $13 \%$ in patients who pass the SBT $[4,11,28]$, regardless of whether it lasts 30 or $120 \mathrm{~min}$ $[9,24]$. However, recent data showed that there might be patients who succeed in the $30 \mathrm{~min}$ trial but fail the $120 \mathrm{~min}$ trial [20].

It is, however, important to point out that the SBT was originally established for intubated patients $[4,7,10,11,15,17$, $22,24,25,28,30,31]$ but has since been adopted for tracheostomized patients, even though there is no evidence to suggest that the classic criteria for the SBT are also valid for these patients. This is particularly important for patients with underlying severe chronic respiratory failure who are undergoing prolonged weaning, especially because the weaning process in this patient group takes up a significant proportion of the total mechanical ventilation time; if weaning eventually fails, it then becomes necessary to continue invasive mechanical ventilation in the home environment (home mechanical ventilation, HMV) via a tracheostoma $[5,14,27]$. The current trial therefore focused on these particular subjects and specifically tested whether the SBT is applicable to subjects who have undergone prolonged weaning.

\section{Materials and methods}

The study protocol was approved by the Ethics Committee at the Witten/ Herdecke University, Witten, Germany (protocol number 98/2014). The study was prospectively performed at a specialized weaning unit for prolonged weaning at the Department of Pneumology, Cologne-Merheim Hospital, University Witten/Herdecke, Cologne, Germany. The study was carried out in accordance with the ethical standards laid down in the Declaration of Helsinki (last revised in October 2013). The study was registered at the German Clinical Trials Register (DRKS00006744; Universal Trial Number: U1111-1161-7111). Informed written consent was obtained from all subjects or legal guardians.

\section{Subjects}

Adult subjects ( $\geq 18$ years) were consecutively enrolled if they were admitted to the specialized weaning unit for an elective check-up of the invasive HMV that they had been using for at least 2 months. Prior to the study, all subjects were established on invasive HMV following weaning failure. All subjects had to have been 


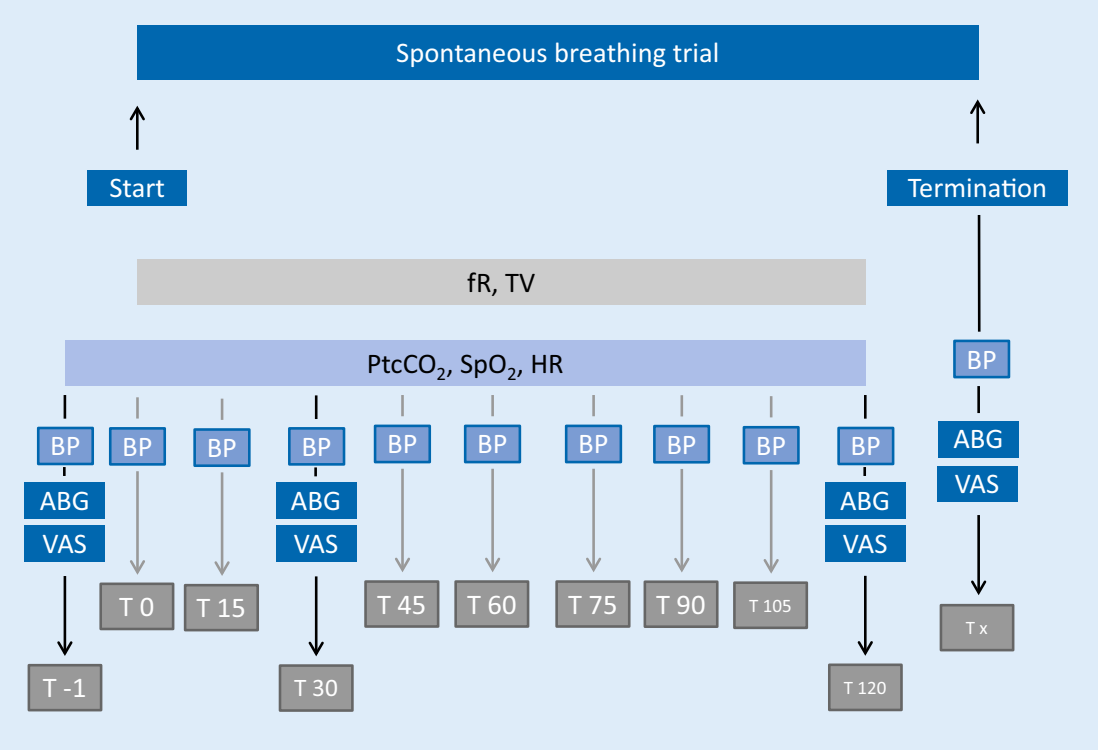

Fig. $1 \Delta$ Study flowchart. $A B G$ arterialized blood gas analysis, $B P$ blood pressure (check for arrhythmias simultaneously), $f R$ respiratory frequency, $\mathrm{HR}$ heart rate, $\mathrm{PtcCO}$ transcutaneous $\mathrm{PCO}_{2}$ monitoring, $\mathrm{SpO}_{2}$ peripheral oxygen saturation, $T$ time (minutes), $V T$ tidal volume, $V A S$ visual analogue scale (dyspnoea, fear, pain)

in a clinically stable disease state during the 2 weeks preceding recruitment, with no signs of respiratory infection (defined by at least two of the following criteria: purulent sputum, temperature $>38.0^{\circ} \mathrm{C}$, pulmonary infiltrates on chest $\mathrm{X}$-ray, leukocyte count $>10,000 / \mathrm{L}$ ) and no changes in their pharmaceutical and nonpharmaceutical treatment regime. In addition, subjects had to fulfil the criteria for readiness to wean in accordance with the 2005 International Consensus Conference recommendations [3].

\section{Data sources}

The following data was collected from each patient: demographics; main diagnosis and co-morbidities; medication; mechanical ventilation details: ventilator type and settings; ventilator protocols established for the home environment (mechanical ventilation times and spontaneous breathing).

\section{Study design}

The study flowchart is presented in - Fig. 1.

Blood pressure was measured noninvasively (M1574A, Philips, Amsterdam, Netherlands; monitor: IntelliVue MP30;
Philips Medical Systems, Boeblingen, Germany), while the degrees of dyspnoea, fear and pain were assessed via a $100 \mathrm{~mm}$ visual analogue scale (VAS) [23]. Blood gas analysis was performed on blood samples from the arterialized earlobe (ABL800 Flex, Radiometer Medical ApS, Brønshøj, Denmark) [21]. Transcutaneous $\mathrm{PCO}_{2}\left(\mathrm{PtcCO}_{2}\right)$ monitoring was performed throughout the entire study period (Sentec Digital Monitor System, SDMS; SenTec AG, Therwil, Switzerland, V07.03.0, V-STATS ${ }^{\circledR}$ 4.00). For this purpose, the sensor was placed on the forehead at least $15 \mathrm{~min}$ prior to the SBT to allow for equilibrium measurements. Continuous heart rate (HR) and peripheral oxygen saturation $\left(\mathrm{SpO}_{2}\right)$ measurements were made simultaneously using the same monitoring system.

For the purpose of the study, each patient underwent an SBT. Disconnecting the patient from the ventilator defined the start of the SBT (T0). To assess the breathing pattern during the SBT, pneumotachographical measurements were performed with a flow sensor (REF 281637; Hamilton Medical AG, Bonaduz, Switzerland) placed between the tracheal cannula and the heat and moisture exchanger (REF 1873000; Intersurgical
GmbH, Sankt Augustin, Germany). Continuous spirometric measurements (AD Instruments, Therwil, Switzerland) were also performed. Data were assessed by PowerLab (AD Instruments, Sydney, Australia) and analysed using specialized software (labchart, AD Instruments, Sydney, Australia). The RSBI was calculated using the mean values for respiratory frequency (fR) and tidal volume (VT); here, a single value was exported from the software every $30 \mathrm{~s}$ and a mean value was calculated from groups of 10 single values at a time.

The SBT was scheduled for $120 \mathrm{~min}$. SBT failure criteria were defined in accordance with the literature (- Table 1 [3]).

If a failure criterion was fulfilled, the SBT was terminated prior to its scheduled end and the reason for termination was documented. However, if a patient insisted on continuing with spontaneous breathing despite the fulfilment of a failure criterion, the SBT was continued under close observation. If the patient did not fulfil any failure criteria within $120 \mathrm{~min}$, the SBT was rated as successful and spontaneous breathing was continued until it was no longer possible, at which point the reason for becoming reconnected to the ventilator was documented. If the SBT was terminated due to clinical criteria, the specific criterion that led to termination (fear, dyspnoea or pain) was documented.

\section{Statistical analysis}

All analyses were performed using SigmaPlot 12.0 (Systat Software GmbH, Erkrath, Germany). For continuous measurements (RSBI, VT, fR, $\mathrm{PtcCO}_{2}$, $\mathrm{SpO}_{2}$ and $\mathrm{HR}$ ), a single parameter was exported from the software every $30 \mathrm{~s}$. Normal data distribution was assessed using the Kolmogorov-Smirnov test. Statistical significance was calculated using the $t$-test for normally distributed data and the Mann-Whitney rank sum test for non-normally distributed data. Statistical significance was assumed at a $p$-value $<0.05$. All analyses are exploratory, without prior planning of sample size. No adjustment for multiple testing was performed. All $p$-values 
Med Klin Intensivmed Notfmed 2020 • 115:300-306 https://doi.org/10.1007/s00063-019-0599-y

(c) Springer Medizin Verlag GmbH, ein Teil von Springer Nature 2019

\section{F. S. Magnet · E. Heilf $\cdot$ S. E. Huttmann · J. Callegari · S. B. Schwarz ·J. H. Storre $\cdot$ W. Windisch}

\section{The spontaneous breathing trial is of low predictive value regarding spontaneous breathing ability in subjects with prolonged, unsuccessful weaning}

\section{Abstract}

Background. The spontaneous breathing trial (SBT) is a well-established diagnostic test for predicting extubation failure in intubated intensive care unit (ICU) patients. However, the SBT has not been evaluated in a specific cohort of tracheostomized patients in whom weaning is prolonged and ultimately unsuccessful.

Objective. The aim of the trial was to investigate the relevance of SBT failure criteria in chronic respiratory failure subjects undergoing long-term invasive home mechanical ventilation following tracheostomy and weaning failure.

Methods. Measurement of all established failure criteria including pneumotachygraphical assessment of the rapid shallow breathing index (RSBI) took place during an SBT. The decision to continue spontaneous breathing was based on failure criteria as well as the subjective willingness of the patient.

Results. Fifteen subjects with a median age of 58 years (interquartile range [IQR] 44-74) were studied; 10 with COPD, 4 with neuromuscular diseases and 1 with both. Twelve subjects met the SBT failure criteria within $30 \mathrm{~min}$, but one third of these subjects were still able to continue with spontaneous breathing. In contrast, 3 subjects could not be weaned despite the SBT being successful. An increased RSBI was the most frequently observed SBT failure criterion ( $57 \%$ of all SBT). However, the
SBT varied substantially in individual subjects who were able to sustain spontaneous breathing, despite having reached the cut-off for SBT failure.

Conclusion. The SBT was of low predictive value regarding spontaneous breathing ability in chronic respiratory failure subjects with prolonged, unsuccessful weaning.

\section{Keywords}

Chronic respiratory failure $\cdot$ Invasive mechanical ventilation $\cdot$ Prolonged weaning $\cdot$ Rapid shallow breathing index $\cdot$ Home mechanical ventilation

\section{Der Spontanatemversuch sagt nicht zuverlässig die Fähigkeit zur Spontanatmung bei Patienten mit prolongiertem erfolglosem Weaning voraus}

\section{Zusammenfassung}

Hintergrund. Der Spontanatemversuch (,spontaneous breathing trial", SBT) ist ein etablierter Test, um ein Extubationsversagen bei intubierten Patienten auf der Intensivstation vorauszusagen. Bei tracheotomierten Patienten im prolongierten und schließlich erfolglosen Weaning wurde er bislang jedoch noch nicht systematisch untersucht.

Ziel der Arbeit. Ziel der Studie war es, die Relevanz der definierten SBT-Abbruchkriterien bei tracheotomierten Patienten mit chronischer respiratorischer Insuffizienz und außerklinischer invasiver Langzeitbeatmung nach Weaningversagen zu untersuchen. Material und Methoden. Alle etablierten SBTAbbruchkriterien inklusive pneumotachographischer Messungen des Rapid Shallow Breathing Index (RSBI) wurden während eines
SBT systematisch gemessen. Die Entscheidung, den Spontanatemversuch fortzuführen, wurde anhand der Abbruchkriterien und des subjektiven Wunsches des Patienten getroffen.

Ergebnisse. In die Studie wurden 15 Patienten mit einem medianen Alter von 58 Jahren (Interquartilsabstand, IQR: 44-74) einbezogen (COPD: 10 Patienten, neuromuskulären Erkrankungen: 4 Patienten, beide Erkrankungen: 1 Patient). Bei 12 Patienten wurde innerhalb von 30 min ein Abbruchkriterium erreicht, dennoch konnte ein Drittel dieser Patienten die Spontanatmung fortführen. Jedoch konnten 3 dieser Patienten nicht von der Beatmung entwöhnt werden, obwohl der SBT erfolgreich war. Ein erhöhter RSBI war das am häufigsten erreichte Abbruchkriterium (in $57 \%$ aller SBT). Bei den Patienten, welche die Spontanatmung trotz Erreichen eines SBT-Abbruchkriteriums fortsetzen konnten, variierte der weitere Verlauf des SBT erheblich. Schlussfolgerung. Der SBT ist von geringem prädiktivem Wert, um die Fähigkeit zur Spontanatmung bei Patienten mit chronischer respiratorischer Insuffizienz und prolongiertem erfolglosem Weaning vorauszusagen.

\section{Schlüsselwörter}

Chronische respiratorische Insuffizienz · Invasive Beatmung · Prolongiertes Weaning · Rapid Shallow Breathing Index · Außerklinische Beatmung should be interpreted in a descriptive sense.

The Pearson correlation coefficient was used to compare the actual duration of the current SBT trial to the duration of spontaneous breathing in the outpatient setting, as well as to that recommended by the physician at the last in-patient check-up session. For further analysis, subjects with SBT failure were categorized according to the timepoint at which the trial failed: $1=$ termination of the SBT after $<30 \mathrm{~min}, 2=$ termination of the SBT after $\geq 30 \mathrm{~min}$.

\section{Results}

Fifteen subjects were consecutively enrolled from October 2014 to August 2015. The basic demographic data of the cohort were as follows: $60 \%(n=9)$ were female, median age was 58 years (interquartile range [IQR] 44-74 years), median BMI was $26 \mathrm{~kg} / \mathrm{m}^{2}$ (IQR 20-30), median duration of HMV was 17 months (IQR 6-27 months). The leading reasons for mechanical ventilation were as follows: COPD $(n=10)$, COPD and amyotrophic lateral sclerosis $(n=1)$, neuromuscular disorders $(n=4$ : amyotrophiclateral sclerosis, $n=1$; Duchenne muscular dystrophy, $n=1$; mitochondriopathies, $n=1$; spinal muscular dystrophy, $n=1$ ). 


\section{Table 1 Spontaneous breathing trial failure criteria [1]}

\begin{tabular}{|c|c|}
\hline \multirow{5}{*}{$\begin{array}{l}\text { Subjective } \\
\text { indices and } \\
\text { clinical } \\
\text { assessment }\end{array}$} & Agitation and anxiety \\
\hline & Depressed mental status \\
\hline & Diaphoresis \\
\hline & Cyanosis \\
\hline & $\begin{array}{l}\text { Evidence of increasing effort: increased accessory muscle activity, facial signs of } \\
\text { distress, dyspnoea }\end{array}$ \\
\hline \multirow{8}{*}{$\begin{array}{l}\text { Objective } \\
\text { measure- } \\
\text { ments }\end{array}$} & $\mathrm{PaO}_{2} \leq 50-60 \mathrm{~mm} \mathrm{Hg}$ on $\mathrm{FiO}_{2} \geq 0.5$ or $\mathrm{SaO}_{2}<90 \%$ \\
\hline & $\mathrm{PaCO}_{2}>50 \mathrm{~mm} \mathrm{Hg}$ or an increase in $\mathrm{PaCO}_{2}>8 \mathrm{~mm} \mathrm{Hg}$ \\
\hline & $\mathrm{pH}<7.32$ or a decrease in $\mathrm{pH} \geq 0.07$ units \\
\hline & fR/VT > 105 breaths/min/l (=RSBI) \\
\hline & $f R>35$ breaths/min or increased by $\geq 50 \%$ \\
\hline & $H R>140$ beats/min or increased by $\geq 20 \%$ \\
\hline & RR sys $>180 \mathrm{~mm} \mathrm{Hg}$ or increased by $\geq 20 \%$ or $<90 \mathrm{~mm} \mathrm{Hg}$ \\
\hline & Cardiac arrhythmias \\
\hline \multicolumn{2}{|c|}{$\begin{array}{l}\text { Table modified according to [1] } \\
\mathrm{PaO}_{2} \text { arterial partial pressure of oxygen, } \mathrm{SaO}_{2} \text { arterial oxygen saturation, } \mathrm{FiO}_{2} \text { inspired oxygen } \\
\text { fraction, } \mathrm{PaCO} \text { arterial partial pressure of carbon dioxide, } f R \text { respiratory frequency, } V T \text { tidal volume, } \\
R S B I \text { rapid shallow breathing index, } H R \text { heart rate, } R R \text { sys systolic blood pressure }\end{array}$} \\
\hline
\end{tabular}

Table 2 Individual results of the spontaneous breathing trial (SBT)

\begin{tabular}{|c|c|c|c|c|}
\hline$n=15$ & $\begin{array}{l}\text { Time taken to fulfil the } \\
\text { first failure criterion } \\
\text { (min) }\end{array}$ & $\begin{array}{l}\text { First failure cri- } \\
\text { terion fulfilled }\end{array}$ & $\begin{array}{l}\text { Duration } \\
\text { of SBT } \\
\text { (min) }\end{array}$ & $\begin{array}{l}\text { Type of failure crite- } \\
\text { ria fulfilled }\end{array}$ \\
\hline 1 & 25 & Clinical criteria & 25 & $\mathrm{PaCO}_{2}$, clinical criteria \\
\hline 2 & 30 & $\mathrm{PaCO}_{2}$ & 30 & $\mathrm{PaCO}_{2}, \mathrm{pH}$ \\
\hline 3 & 25 & RSBI & 66 & RSBI \\
\hline 4 & 8 & RSBI & 11 & $\begin{array}{l}\mathrm{PaCO}_{2}, \mathrm{RSBI} \text {, clinical } \\
\text { criteria }\end{array}$ \\
\hline 5 & 6 & Clinical criteria & 6 & $\begin{array}{l}\text { Clinical criteria, } \mathrm{PaCO}_{2}, \\
\mathrm{SpO}_{2}\end{array}$ \\
\hline 6 & 7 & RSBI & 13 & $\mathrm{RSBI}$ \\
\hline 7 & 4 & RSBI & $>120$ & $\mathrm{RSBI}, \mathrm{HR}$ \\
\hline 8 & 0 & RSBI & $>120$ & $\begin{array}{l}\mathrm{PaCO}_{2}, \mathrm{RSBl}, \mathrm{RR} \text { sys, } \\
\text { clinical criteria }\end{array}$ \\
\hline 9 & 90 & RR sys & $>120$ & RR sys \\
\hline 10 & 24 & Clinical criteria & 24 & Clinical criteria \\
\hline 11 & $>120$ & None & $>120$ & None \\
\hline 12 & 0 & RSBI & 30 & $\begin{array}{l}\mathrm{PaCO}_{2}, \mathrm{RSBI} \text {, clinical } \\
\text { criteria }\end{array}$ \\
\hline 13 & 0 & RSBI & 21 & $\mathrm{pH}, \mathrm{SpO}_{2}, \mathrm{RSBI}, \mathrm{fR}$ \\
\hline 14 & 50 & $\mathrm{PaCO}_{2}$ & 50 & $\mathrm{PaCO}_{2}$, clinical criteria \\
\hline 15 & 0 & RSBI & $>120$ & $\mathrm{RSBI}, \mathrm{fR}$ \\
\hline
\end{tabular}

Clinical criteria = agitation and anxiety/depressed mental status/diaphoresis/cyanosis/evidence of increasing effort/increased accessory muscle activity/facial signs of distress/dyspnoea [3]

$f R$ respiratory frequency $>35$ breaths/min or increased by $\geq 50 \%$, HR heart rate $>140$ beats $/ \mathrm{min}$

or increased by $\geq 20 \%, \mathrm{PaCO}_{2}$ arterial partial pressure of oxygen $>50 \mathrm{~mm} \mathrm{Hg}$, or an increase of

$>8 \mathrm{~mm} \mathrm{Hg}, \mathrm{pH}$ pH-value $<7.32$ or a decrease in $\mathrm{pH}$ of $\geq 0.07 \mathrm{pH}$ units, $R R$ sys systolic blood pressure

$>180 \mathrm{~mm} \mathrm{Hg}$ or increased by $\geq 20 \%$ or $<90 \mathrm{~mm} \mathrm{Hg}, R S B I$ rapid shallow breathing index $>105$

breaths/min/l, $\mathrm{SpO}_{2}$ peripheral oxygen saturation $<90 \%$
Nine subjects had cardiovascular comorbidities (e.g. arterial hypertension, atrial fibrillation, heart failure). Overall, 10 subjects were ventilated in an assisted pressure-controlled mode (aPCV), and 5 in a pressure-supported mode (PSV or ST).

The results of the SBT are displayed in 0 Fig. 2.

Overall, twelve subjects fulfilled at least one failure criterion within the first $30 \mathrm{~min}$ of the SBT. Two subjects fulfilled at least one failure criterion between 30 and $120 \mathrm{~min}$, and one patient did not fulfil any failure criteria within $120 \mathrm{~min}$ of the SBT (• Fig. 2).

None of the subjects could eventually be weaned from invasive mechanical ventilation. This was also true for the subjects who had undergone a successful SBT after the first $30 \mathrm{~min}(n=3)$. - Table 2 shows the SBT results of the individual subjects.

Figure 3 shows the distribution of the first failure criterion that was fulfilled.

Eight subjects terminated the SBT after $\leq 30 \mathrm{~min}$ (group 1), and seven subjects after $>30$ min (group 2), irrespective of the failure criteria being fulfilled or not.

Group 1 and 2 were comparable in terms of the following pre-SBT parameters: $\mathrm{PaCO}_{2}(p=0.23), \mathrm{pH}(p=0.51)$, systolic blood pressure $(p=0.86)$, VAS score for dyspnoea $(p=0.17)$, fear $(p=0.61)$ and pain $(p=0.34)$. Furthermore, the RSBI (at the time of disconnection from the ventilator; T0) also did not differ between groups $(p=0.61)$. Overall, the RSBI showed broad intra-individual variation throughout the SBT assessment period, with a standard deviation of 17.6/18.3 breaths/min/l (median/ mean; min-max: 1.7-64.9).

Figure 4 shows the individual recordings of a 32-year-old female patient with spinal muscular atrophy (Kugelberg-Welander) who was on spontaneous breathing for $16 \mathrm{~h} /$ day at home.

Although RSBI measurements showed values greater than 105 breaths/min/l (=failure criteria) from the very start, the patient's clinical status was stable throughout the whole trial and she insisted on continuing with spontaneous breathing. RSBI showed wide variability throughout the measurement period of 


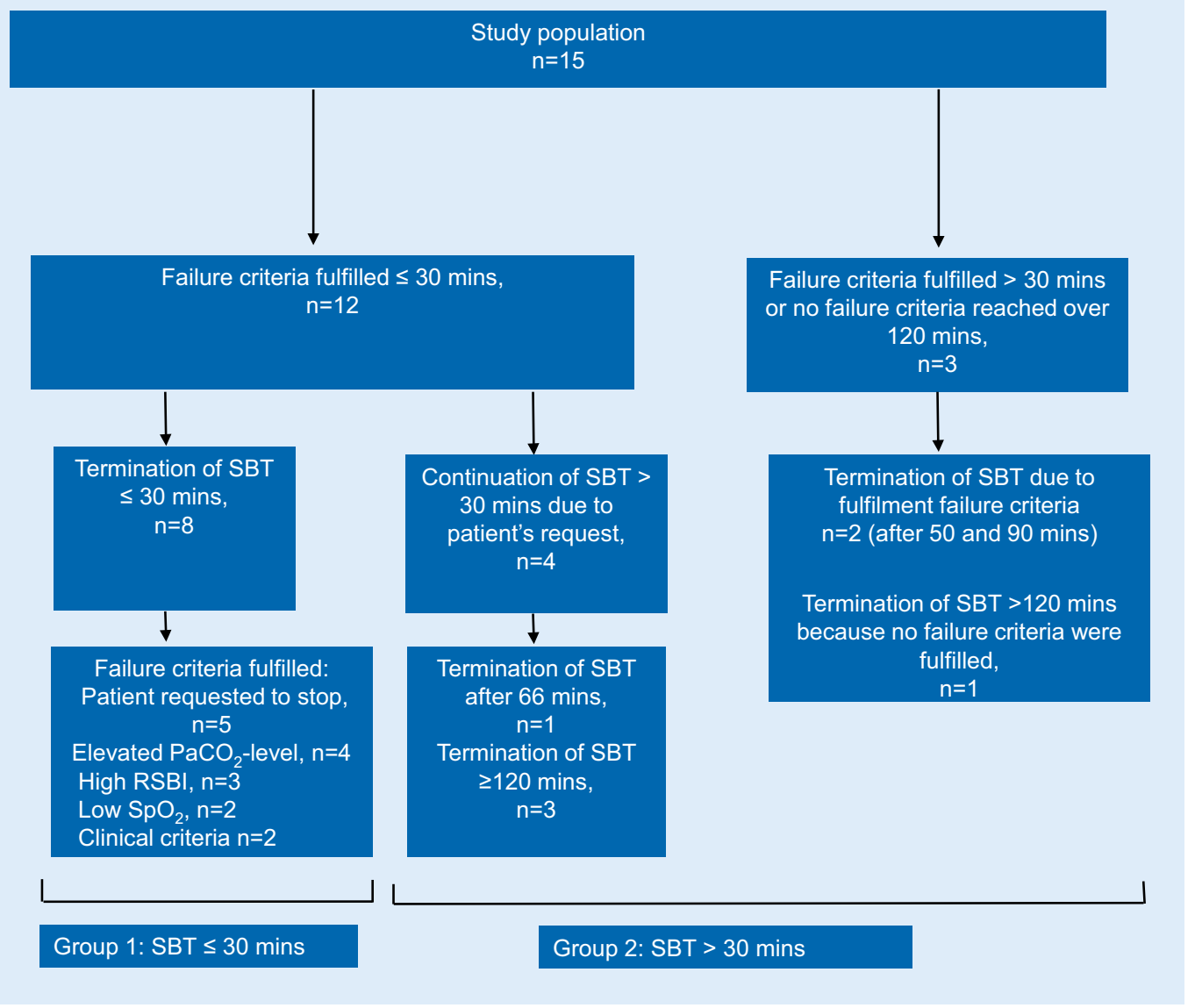

Fig. $2<$ SBT results for the whole study population. mins minutes, $\mathrm{PaCO}_{2}$ arterialized partial pressure of carbon dioxide, $R S B /$ rapid shallow breathing index, SBT spontaneous breathing trial, $\mathrm{SpO}_{2}$ peripheral oxygen saturation

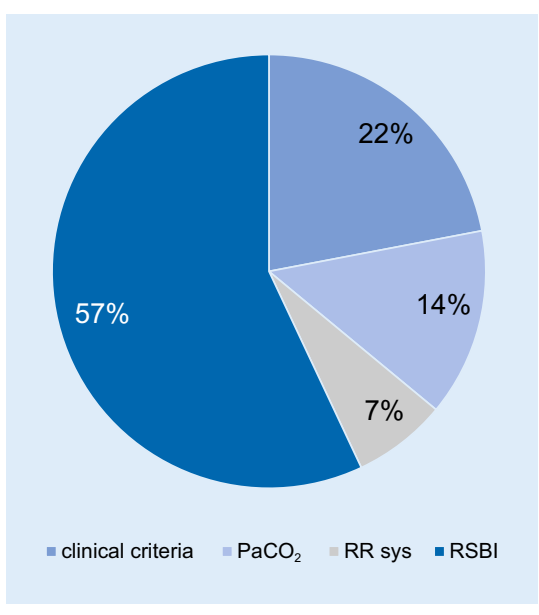

Fig. $3 \Delta$ Distribution of the first failure criterion fulfilled $(n=14)$. $\mathrm{PaCO}_{2}$ arterial partial pressure of carbon dioxide, $R R$ sys systolic blood ores sure, $R S B /$ rapid shallow breathing index

$120 \mathrm{~min}$. The second failure criterion that was fulfilled was breathing frequency $>35$ breaths $/ \mathrm{min}$ after $17 \mathrm{~min}$. VAS scores for pain, dyspnoea and fear were zero throughout the whole trial and are therefore not displayed in the figure.
The mean duration of the spontaneous breathing period recommended by the physician was $2.0 \mathrm{~h} /$ day (median; min-max: $0-19 \mathrm{~h} /$ day). This was highly correlated $(r=0.89, p<0.001)$ with the actual duration of spontaneous breathing at home (median $3.0 \mathrm{~h} / \mathrm{d}$; min-max: $0-17 \mathrm{~h} /$ day), and moderately correlated with the duration of the experimental SBT in the current study ( $30 \mathrm{~min}$ median; min-max: 6->120 min, $r=0.70$, $p=0.004$ ). Importantly, however, this did not correlate with the time taken until the first failure criterion was fulfilled in the current experimental set-up (8 min median; min-max: $0->120 \mathrm{~min}$, $\mathrm{r}=0.12, p=0.70)$.

\section{Discussion}

To the best of our knowledge this is the first trial to evaluate the diagnostic value of SBTs in subjects who were undergoing prolonged weaning from invasive HMV that was ultimately unsuccessful. The main result of the study was that the SBT did not provide useful information for predicting the ability to maintain spontaneous breathing in subjects with prolonged weaning. On one hand, none of the subjects who had a successful SBT were eventually able to be weaned from invasive mechanical ventilation. On the other, many of the subjects who fulfilled specific failure criteria for the SBT were still able to continue spontaneous breathing for many hours, even in cases of severe physiological disturbances. For example, even subjects with an extremely high RSBI during the first $30 \mathrm{~min}$ of spontaneous breathing were able to maintain spontaneous breathing for many hours. Finally, there was discordance between the subjective comfort during spontaneous breathing vs. the physiological parameters assessed during the SBT. Taken together, the SBT-which was originally transferred from an ICU setting to subjects with prolonged weaning - may therefore not be useful in this patient cohort. 


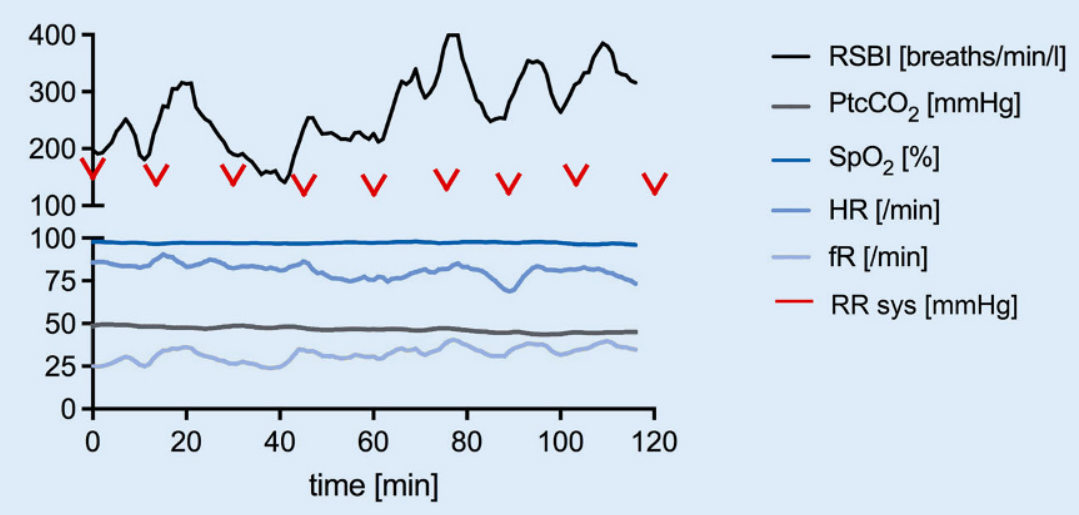

Fig. $4 \Delta$ Individual recordings from a 32-year-old patient with spinal muscular atrophy. $f R$ respiratory frequency, $\mathrm{HR}$ heart rate, $\mathrm{PtcCO}$ transcutaneous partial pressure of carbon dioxide, RR sys systolic blood pressure, $\mathrm{RSB}$ r rapid shallow breathing index, $\mathrm{SpO}_{2}$ peripheral oxygen saturation. VAS scores for pain, dyspnoea and fear were zero throughout the whole trial

Data for the prognostic value of the SBT stem from ICU medicine. Here, most patients are assigned to the 'easy' or 'difficult' weaning $[4,7,9,11,12]$ rather than 'prolonged' weaning categories. In contrast to patients with easy or difficult weaning, patients undergoing prolonged weaning mostly suffer from chronic respiratory failure, and many also have significant comorbidities that affect respiratory mechanics [9]. This might explain why prolonged-weaning patients respond differently to the physiological parameters covered by the SBT. In addition, patients are likely to have adapted to a more 'rapid shallow breathing' pattern during the course of their disease and may therefore tolerate higher RSBIs for a longer period of time. Moreover, the RSBI in ICU medicine is usually measured via an orotracheal rather than a tracheal tube, which was exclusively the case in the current cohort.

As already emphasized by Yang and Tobin back in 1991, the RSBI is the best index for evaluating the SBT [30], although it has a variable specificity and sensitivity $[16,19,26]$ and several trials observed a wide range of different predictive values for RSBI, depending on the different study population and classification of outcomes $[1,28,29]$.

However, it has not been clarified how long the RSBI can remain above 105 breaths/min/l before the SBT has to be terminated. Interestingly, in this trial, high individual variations in RSBIs were
Even though the International Consensus Conference data published over 10 years ago described the SBT as a wellaccepted predictor of successful weaning [3], a very recent epidemiological study covering 2729 subjects concluded that many of the subjects treated on the ICU cannot be categorized according to the results of the SBT, because this particular trial is not always performed in clinical practice [2]. A different categorization scheme for the degree of weaning failure severity was therefore proposed, which is independent from performing an SBT [2]. Indeed, the SBT is a technically complex procedure in patients with prolonged weaning, as demonstrated in the current study. Given the fact that the SBT is yet to be convincingly adapted for use in the specific cohort of prolonged weaning, in contrast to intubated patients receiving short-term invasive mechanical ventilation, the current study doubts that the SBT-as recommended by guidelines-is a worthwhile tool for predicting spontaneous breathing capabilities in prolonged, unsuccessful weaning. Clearly, further studies adding to the current pilot testing are necessary to validate this observation.

There are some limitations to this study that need to be addressed. Firstly, it is a strictly observational trial in which the statistical data serve as exploratory and descriptive findings only. Secondly, the sample size was rather small due to the special inclusion criteria.

\section{Conclusion}

In conclusion, the standard SBT established for intubated ICU patients is prone to both over- and underestimation of the ability to breathe spontaneously in patients with prolonged, unsuccessful weaning. Therefore, the SBT does not provide useful information for predicting subsequent spontaneous breathing patterns in the specific cohort of prolongedweaning patients. 


\section{Corresponding address}

\section{Dr. med. F. S. Magnet}

Department of Pneumology, Cologne Merheim Hospital, Kliniken der Stadt Köln gGmbH Ostmerheimer Straße 200, 51109 Cologne, Germany magnetf@kliniken-koeln.de

Acknowledgements. All participants are acknowledged for the effort they devoted to this study and Dr. Sandra Dieni for helpful comments on the manuscript.

\section{Compliance with ethical guidelines}

Conflict of interest F.S. Magnet, E. Heilf, S.E. Huttmann, J. Callegari, S.B. Schwarz, J.H. Storre and W. Windisch report open research grants from Weinmann/Germany, Vivisol/Germany, Heinen und Löwenstein/Germany, VitalAire/Germany and Philips/ Respironics/USA, during the conduct of the study. F.S. Magnet reports travel grants from Heinen und Löwenstein/Germany, grants for travel and advisory board from Philipps Respironics/Germany and speaker fees from SenTec/Switzerland, outside the submitted work. J.H. Storre reports personal fees for lectures from Heinen und Löwenstein/Germany, VitalAire/Germany and Vivisol $\mathrm{GmbH}$; financial support for attending congresses from Vivisol $\mathrm{GmbH}$; and personal fees for expertise/advisory board from Breas Medical during the conduct of the study. He reports personal honoraria for expertise/lectures and financial support for attending congresses from Boehringer Ingelheim Pharma; honoraria for expertise/lectures from SenTec AG, Keller Medical GmbH, Keller Medical GmbH, Linde Deutschland and Santis $\mathrm{GmbH}$ outside the submitted work. W. Windisch reports speaker fees from companies dealing with mechanical ventilation outside the submitted work.

The study protocol was approved by the Ethics Committee at the Witten/Herdecke University, Witten, Germany (protocol number 98/2014). The study was carried out in accordance with the ethical standards laid down in the Declaration of Helsinki (last revised in October 2013). Informed written consent was obtained from all subjects or legal guardians.

\section{References}

1. Banerjee A, Mehrotra G (2018) Comparison of lung ultrasound-based weaning indices with rapid shallow breathing index: are they helpful? Indian J Crit Care Med 22:435-440

2. Beduneau G, Pham T, Schortgen F et al (2017) Epidemiology of weaning outcome according to a new definition. The WIND study. Am J Respir Crit Care Med 195:772-783

3. Boles JM, Bion J, Connors A et al (2007) Weaning from mechanical ventilation. Eur Respir J 29:1033-1056

4. Brochard L, Rauss A, Benito S et al (1994) Comparison of three methods of gradual withdrawal from ventilatory support during weaning from mechanical ventilation. Am J Respir Crit Care Med 150:896-903
5. Bruells CS, Bickenbach J, Marx G (2018) Weaning ward-different from the ICU? Med Klin Intensivmed Notfmed 113:94-100

6. Ely EW, Baker AM, Dunagan DP et al (1996) Effect on the duration of mechanical ventilation of identifying patients capable of breathing spontaneously. N Engl J Med 335:1864-1869

7. Esteban A, Alia I, Gordo F et al (1997) Extubation outcome after spontaneous breathing trials with T-tube or pressure support ventilation. The Spanish Lung Failure Collaborative Group. Am J Respir Crit Care Med 156:459-465

8. Esteban A, Alia I, Ibanez J et al (1994) Modes of mechanical ventilation and weaning. A national survey of Spanish hospitals. The Spanish Lung Failure Collaborative Group. Chest 106:1188-1193

9. Esteban A, Alia I, Tobin MJ et al (1999) Effect of spontaneous breathing trial duration on outcome of attempts to discontinue mechanical ventilation. Spanish Lung Failure Collaborative Group. Am J Respir Crit Care Med 159:512-518

10. Esteban A, Anzueto A, Frutos F et al (2002) Characteristics and outcomes in adult patients receiving mechanical ventilation: a 28 -day international study. JAMA 287:345-355

11. Esteban A, Frutos F, Tobin MJ et al (1995) A comparison of four methods of weaning patients from mechanical ventilation. Spanish Lung Failure Collaborative Group. N Engl J Med 332:345-350

12. Farias JA, Retta A, Alia l et al (2001) A comparison of two methods to perform a breathing trial before extubation in pediatric intensive care patients. Intensive Care Med 27:1649-1654

13. Figueroa-Casas JB, Connery SM, Montoya R (2015) Changes in breathing variables during a 30 minute spontaneous breathing trial. Respir Care 60:155-161

14. Geiseler J, Kelbel C (2016) Weaning from mechanical ventilation. Weaning categories and weaning concepts. Med Klin Intensivmed Notfmed 111:208-214

15. Haberthur C, Mols G, Elsasser S et al (2002) Extubation after breathing trials with automatic tube compensation, T-tube, or pressure support ventilation. Acta Anaesthesiol Scand 46:973-979

16. Huang CT, Yu CJ (2013) Conventional weaning parameters do not predict extubation outcome in intubated subjects requiring prolonged mechanical ventilation. Respir Care 58:1307-1314

17. Jones DP, Byrne P, Morgan C et al (1991) Positive end-expiratory pressure vs T-piece. Extubation after mechanical ventilation. Chest 100:1655-1659

18. Kollef MH, Shapiro SD, Silver P et al (1997) A randomized, controlled trial of protocoldirected versus physician-directed weaning from mechanical ventilation. Crit Care Med 25:567-574

19. Lee KH, Hui KP, Chan TB et al (1994) Rapid shallow breathing (frequency-tidal volume ratio) did not predict extubation outcome. Chest 105:540-543

20. Liang G, Liu T, Zeng Y et al (2018) Characteristics of subjects who failed a 120-minute spontaneous breathing trial. Respir Care 63:388-394

21. Magnet FS, Majorski DS, Callegari J et al (2017) Capillary PO2 does not adequately reflect arteria PO2 in hypoxemic COPD patients. Int J Chron Obstruct Pulmon Dis 12:2647-2653

22. Matic I, Majeric-Kogler V (2004) Comparison of pressure support and T-tube weaning from mechanical ventilation: randomized prospective study. Croat Med J 45:162-166

23. Mccormack HM, Horne DJ, Sheather S (1988) Clinical applications of visual analogue scales: a critical review. Psychol Med 18:1007-1019
24. Perren A, Domenighetti G, Mauri S et al (2002) Protocol-directed weaning from mechanical ventilation: clinical outcome in patients randomized for a 30-min or 120-min trial with pressure support ventilation. Intensive Care Med 28:1058-1063

25. Reissmann HK, Ranieri VM, Goldberg $P$ et al (2000) Continuous positive airway pressure facilitates spontaneous breathing in weaning chronic obstructive pulmonary disease patients by improving breathing pattern and gas exchange. Intensive Care Med 26:1764-1772

26. Savi A, Teixeira C, Silva JMet al (2012) Weaning predictors do not predict extubation failure in simpleto-wean patients. J Crit Care 27(221):e221-e228

27. Schonhofer B, Geiseler J, Dellweg Detal (2015) S2kGuideline "Prolonged Weaning". Pneumologie 69:595-607

28. Vallverdu I, Calaf N, Subirana M et al (1998) Clinical characteristics, respiratory functional parameters, and outcome of a two-hour T-piece trial in patients weaning from mechanical ventilation. Am J Respir Crit Care Med 158:1855-1862

29. Yan S, Lichros I, Zakynthinos S et al (1993) Effect of diaphragmatic fatigue on control of respiratory muscles and ventilation during $\mathrm{CO} 2$ rebreathing. JAppl Physiol 75:1364-1370

30. Yang KL, Tobin MJ (1991) A prospective study of indexes predicting the outcome of trials of weaning from mechanical ventilation. $\mathrm{N}$ Engl J Med 324:1445-1450

31. Zeggwagh AA, Abouqal R, Madani N et al (1999) Weaning from mechanical ventilation: a model for extubation. Intensive Care Med 25:1077-1083 